\title{
OCEANOGRAPHY IN THE DECADE OF DIGITAL SCIENCE AND SUSTAINABLE DEVELOPMENT New Opportunities for TOS?
}

The key word in our society's name, oceanography, combines the

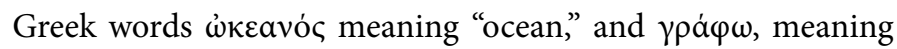
"write." Other languages use oceanology, with the second word

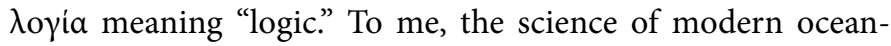
ography includes both the description and the understanding of ocean systems that cover a wide range of topics, including marine life and ecosystems, ocean circulation, plate tectonics and the geology of the seafloor, and the ocean's chemical, biogeochemical, and physical properties. Since the beginning of The Oceanography Society (TOS), we have recognized four scientific disciplines with seats on our Council-physical, biological, chemical, and geological oceanography-and we recognize the importance of applied technology and education. I'd like to suggest that to keep TOS-the only international society that bridges all areas of ocean science-current, it is time to revisit its disciplinary building blocks.

Erik van Sebille, one of the invited lecturers at the recent Ocean Sciences Meeting, introduced himself as a "plastic oceanographer" with a twinkle in his eye. And Jane Lubchenco, in her Mary Sears Medal lecture, ended with a call to action for our community to "embrace a new social contract, one in which scientists and their institutions are fully engaged in co-creating scalable solutions that heal people and the ocean." These words parallel an agenda that the UN Decade of Ocean Science for Sustainable Development will promote during 2021-2030. We need to ask ourselves whether TOS embraces all ocean disciplinary communities needed to support these emerging challenges.

I also saw a large number of contributions at the Ocean Sciences Meeting in the area of "digital oceanography." About 15 abstracts explicitly mentioned the word "digital," 20 included "artificial intelligence," another 20 referred to "big data," and more than 50 used "machine learning" methods. The European Union is currently discussing a Mission Earth initiative that would bring together scientific and industrial excellence to develop a high-precision digital model of Earth (its "digital twin") that would radically improve Europe's environmental prediction and crisis management capabilities. Is TOS ready to support the ocean's piece? I am excited about an OCEAN5D initiative supporting "digital twin oceans" that would describe

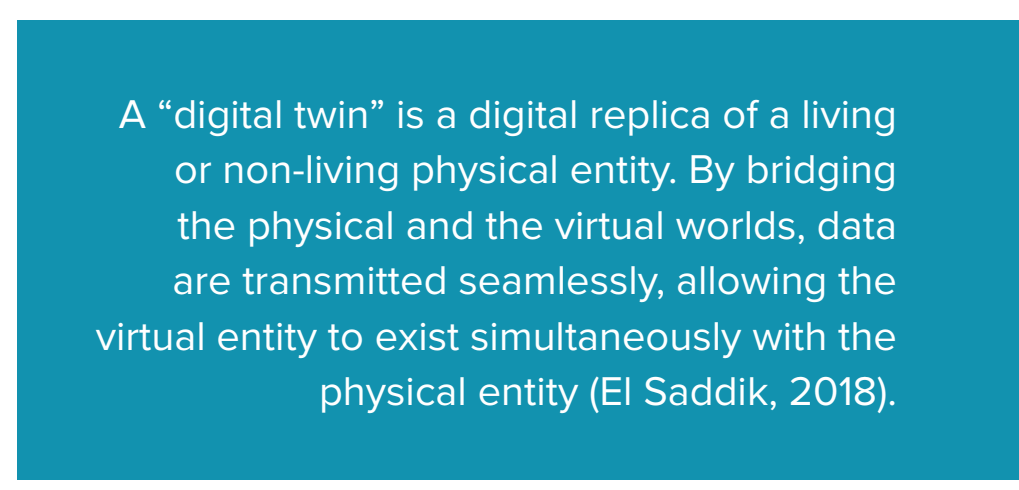

an ocean in one temporal and three spatial dimensions (4D). The fifth dimension would refer to an ocean issue such as seafloor habitat, sea level changes, seagrass abundance, coastal vulnerability to harmful algae blooms, or the economic potential of zoning for mariculture or wind energy farming. If all of our existing data were interoperable and FAIR (for details, see https://www.go-fair.org/fair-principles/), we could deliver the first OCEAN5D pilots rapidly at regional or sub-basin scales. The US EarthCube initiative (https://www.earthcube.org/) seems like a most relevant step in the direction of open and interoperable environmental data.

For TOS to capitalize on these ideas, we should consider enlarging our Council by two members, one to connect us to the socioeconomic-legal ocean communities and another to represent the digital dimension of oceanography. Moreover, should we consider cosponsoring two topical ocean meetings in 2021, perhaps one on ocean solutions in partnership with the Ocean Visions network (http://www.oceanvisions.org/) and another on the digital ocean jointly with IEEE (https://www.ieee.org/)? I am interested to hear your thoughts and ideas.

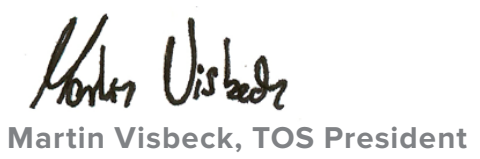

REFERENCE

El Saddik, A. 2018. Digital twins: The convergence of multimedia technologies. IEEE MultiMedia 25(2):87-92, https://doi.org/10.1109/MMUL.2018.023121167. 